\title{
A Contribution of the Students of Architecture to the Salvage of the Industrial Heritage in the Czech Republic
}

\author{
HELENA ZEMANKOVA \\ Technical University of Brno \\ Czech Republic
}

The history of the European towns is a history of their successful periods, new town-planning solutions with redevelopments and developments of objects, extensions to the existing buildings or their new functional uses.

Since antiquity up to the present time the whole fragments of towns have been redeveloped in the existing town structures. The architects have been re-considering the work of their predecessors, redeveloping them, re-interpreting their architectonic notions, and re-using the existing architectonic schemes. Towns which have grown naturally reflecting their history are characterized by a creative continuity which can be taken as an inspiration for the future.

After World War II, the rate of the town-planning development was accelerated in the industrially developed countries. The decline of the outdated industry from the era of industrialization together with incorrectly applied townplanning instruments brought about extensive demolitions of production areas often situated in the immediate vicinity of town centres. This, in turn, created a number of dormant areas. The productive and storing functions of objects situated in areas, whose price had soared as a consequence of their position in the towns, were transferred to monofunctional zones in the suburbs, and all traces of previous production activities vanished from the town centres.

It was not until the seventies that the industrial architecture became the object of interest. These new approaches of architects and town-planners, but also of the members of parliament, are connected with the appreciation of the quality and architectonic uniqueness of the old production areas, but above all with the problems of demolitions and criticism of building big monofunctional areas. The new approach is also seen in a number of European towns where the process of revitalization also includes conversions of objects as conscious creative town-planning and architectonic works with participation of renowned architects.

Also the Czech and Moravian architects at present are facing serious problems of creating conceptions and formulating programmes of gradual re-vitalization of old parts of most towns in the Czech Republic. The changes in the social and economic structure which have been going on in the Czech Republic for the last four years have brought about the termination of some objects and production areas. The economic changes put some of the productions out of use, creating dormant production areas even in the conditions of the Czech Republic. The government launches a number of production cut programmes in the mining industry and other branches. The mines in Ostrava and the surrounding regions, which have influenced the urban design of the town, are now terminating their activities. These are very typical areas with mixed manufacturing, servicing, and housing functions with valuable architecture of specialized and dominant buildings - the symbols of this region.

Brno - a town famous for its textile industry - is also known as the Moravian Manchester. At present, nine textile factories are stagnating in this largest town of Moravia. Their positions in the vicinity of the town centre predestine them for new uses supplying the numerous missing urban facilities. In South Moravia it is the production of sugar that has been providing a great number of jobs in agriculture in growing the sugar beet - sometimes called "the white gold" - and also in its subsequent processing in sugar mills. The termination of these productions has left vacated production areas in the central parts of many Moravian towns.

This brings assignments for the architects and townplanners but also for students of architecture. At the Faculty of Architecture of the Technical University of Brno they are taught in special courses in conversion how to set up criteria for evaluating the vacated buildings, find ways of their salvage and new use, design the course of actions necessary for their reactivation and collect the existing documentation and studies of functional changes. Successful conversions in industrial West European towns show us that the conversion can also be a sociological operation, as is the case in the North of France where the towns "injected" a new dynamic into their centres by functional changes of their old textile factories thus enabling a stabilization of labour market and population growth in the long run. 